Brief report

\title{
Functional or nonfunctional cusps preservation for posterior onlays in indirect composite or glass-ceramic: 3D FEA Study
}

\author{
Pablo Lenin Benitez Sellan ${ }^{1}$, Larissa Mendes Campaner ${ }^{1}$, João Paulo Mendes Tribst ${ }^{2}$, Amanda Maria de Oliveira \\ Dal Piva ${ }^{2}$, Guilherme Schmitt de Andrade ${ }^{3}$, Alexandre Luiz Souto Borges ${ }^{1}$, Eduardo Bresciani ${ }^{1}$, Pietro Ausiello ${ }^{4 *}$. \\ 1 Institute of Science and Technology, São Paulo State University (Unesp), São José dos Campos, São Paulo \\ 12220690, Brazil; pablo.benitez@unesp.br; larissa.m.campaner@unesp.br; alexander.borges@ict.unesp.br; \\ eduardo.bresciani@unesp.br \\ 2 Department of Dental Materials, Academic Centre for Dentistry Amsterdam (ACTA), University of Amster- \\ 9 dam and Vrije Universiteit Amsterdam, Amsterdam, the Netherlands, 1081 LA Amsterdam, The Nether- \\ 10 lands; amodalpiva@gmail.com; joao.tribst@gmail.com \\ 3 Department of Dentistry, Center for Biological and Health Sciences, Western Paraná State University (Un- \\ ioeste), Cascavel, Paraná, Brazil; guilherme.andrade@unesp.br \\ 4 School of Dentistry, University of Naples Federico II, 80131 Naples, Italy; pietausi@unina.it \\ * Correspondence: pietausi@unina.it
}

\begin{abstract}
Evidence regarding the effect of the onlay preparation design for different CAD/CAM restorative materials considering the preservation of cusps is lacking. Molars were 3D modeled in four preparation designs for onlay restoration: traditional design with functional cusp coverage (TFC), non-retentive design with functional cusp coverage (NFC), traditional design with non-functional cusp coverage (TNFC), non-retentive design with non-functional cusp coverage (NNFC). Restorations were simulated with two CAD/CAM restorative materials: LD - lithium disilicate (IPS e.max CAD) and RC - resin composite (GrandioBloc). A $100 \mathrm{~N}$ axial load was applied to the occlusal surface simulating the centric contact point. Von Mises (VM) and maximum principal (Pmax) stresses were evaluated for restorations, cement layer and dental substrate. The non-retentive preparation design reduced the stress concentration in the tooth structure in comparison to the conventional retentive design. For LD onlays, the stress distribution on the restoration intaglio surface showed that the preparation design as well as the prepared cusp, influenced the stress magnitude. The non-retentive preparation design provided better load distribution in both restorative materials and more advantageous for tooth structure. The resin composite restoration on non-functional cusp is recommended when functional cusp is preserved, in order to associate conservative dentistry and low stress magnitude.
\end{abstract}

Keywords: dental materials; finite element analysis; prosthodontics; biomechanics

\section{Introduction}

In the last decade, restorations made using the CAD/CAM methodology have been gaining attention. The lithium disilicate for dental restorations was introduced in 2006 and it is marketed in a pre-crystalline phase that, after machining, undergoes a firing process to reach the final selected color [1]. Several clinical studies with full and partial overlay restorations have been carried out with this material showing promising results [2-4]. In a literature review, conducted by Pieger et al., with the inclusion of research with lithium disilicate glass-ceramic, a $97.8 \%$ survival rate was observed in 5 years of follow-up [5].

Although the success rates for dental ceramics are high, there are still some clinical situations that require improvement. There are limitations in posterior teeth, where there is a greater masticatory load than in anterior teeth, which might compromise those 
posterior restoration, making them more vulnerable to failure [6]. The distribution of occlusal forces in individuals with no occlusal changes is greater in the molar region, reaching an average maximum force of $400 \mathrm{~N}$ while in individuals with some parafunctional habits, as in the cases of bruxism, this force can reach values even $1000 \mathrm{~N}[7,8]$. Some of the failures that can occur due to the limitations of this type of material are cracks or catastrophic fractures, inadequate marginal adjustment and wear of antagonistic teeth opposed to the restoration $[9,10]$.

The damage tolerance of lithium disilicate does not only depend on the manufacturing method, but also on the fracture toughness presented by this material. The toughness mechanism seems to be influenced by the size of the crystals, since they prevent the spread of cracks that can lead to catastrophic failure [11]. This ceramic presented a survival rate of $96.3 \%$ in two years when analyzing a retrospective study of onlay restorations, being made and evaluated 37 restorations, of which 31 were with reinforced glassceramic and of these 5 restorations failed, being 3 by fracture [12].

A critical factor comparing the pressed and machined lithium disilicate restorations is the marginal adjustment, which can present mismatch, leading to deleterious effects such as marginal staining, cement degradation or secondary caries [5]. In a review of the two techniques for making the restoration, it was concluded that the presses obtained a smaller marginal crack than the machined ones [13]. In this way, the quality of the preparation for CAD/CAM restorations must be more refined and uniform, with no retentions that can prevent adaptation [14].

Making use of a material that has a friendly behavior with the tooth structure would be an interesting alternative to circumvent the failures of restorations, since commercially there are blocks such as hybrid type ceramics or nanoresins with a greater amount of fillers [15,16]. One of these types of blocks was launched in 2013 and is commercially distributed by VOCO under the name of Grandio Blocs. The composition of this material with $86 \%$ inorganic filler content results in greater strength and stability $[17,18]$.

According to the manufacturer, the elastic modulus of the composite nanoresins shows values between the ceramic and indirect composite resins, thus having a flexural strength of $330 \mathrm{MPa}$ [19]. These data lead us to believe that this type of material can have a superior clinical behavior in relation to catastrophic failures when compared to porcelain and even glass-ceramics, in addition to reducing the need to wear antagonistic teeth and wear of antagonistic teeth. The indications, according to the manufacturers, are for inlays, onlays, overlays, single crown restorations and in some cases can be used in areas of greater stress [20].

Cavity preparation design can be one of the main reasons for tooth fracture or restoration [21]. When the tooth loses more of its structure, especially the marginal ridge, the cavity becomes more susceptible to deformations when stressed. Unlike metallic restorations, ceramic restorations with traditional preparations, due to their fragile nature, do not support occlusal loads when they involve the coverage of the cusp of the dental structure [22]. Several studies have offered different designs on the preparation of the cavity, ideal for restorations of partial ceramic covering [23-25] as well as for the cement layer polymerization kinetics [25,26].

When the surface of the cavity preparation is flat, even the restoration of the cavity with high adhesive strength material cannot guarantee a stable restoration. The creation of retention can reduce the interfacial adhesive strength and increase the survival rate of the restorations, thus decreasing the probability of early detachment. However, the preparation of the retention grooves sacrifices much of the remaining tooth structure [27], for this reason conventional preparations must adopt minimally invasive approaches, avoiding restoration failures [28], although preparations for partial restoration lead to considerable enamel loss [22].

With the continuous development of dental materials and ceramics with innovative manufacturing processes such as CAD/CAM, the question that arises is whether the 
preparation guidelines for partial ceramic restorations could be adapted for minimally invasive approaches while preserving more healthy tissue. Therefore, the aim of the present study was to biomechanically analyze various preparation designs for lithium disilicate ceramic and resin composite onlays under simulated tensions induced by chewing. In particular, if the risk of fracture is greater with lithium disilicate ceramic restorations than with CAD/CAM resin restorations.

\section{Materials and Methods}

A three-dimensional geometry was obtained with the aid of CAD (Computer Aided Design) software (Rhinoceros ${ }^{\circledR}$ version 4.0 ). The 3D teeth were obtained from a scan of preparations made in resin models, in which the teeth presented anatomy based on the literature. In this step, the models were generated from lines drawn over the image in STL, in which the main anatomical landmarks are chosen, generating lines over them, such as which referenced the surface. Molars were modeled in four preparation designs of onlay restoration: traditional with functional cusp coverage (TFC), non-retentive with functional cusp coverage (NFC), traditional with non-functional cusp coverage (TNFC), non-retentive with non-functional cusp coverage (NNFC).

The design for the traditional onlay preparation was created with a $2.7 \mathrm{~mm}$ depth, $2.3 \mathrm{~mm}$ opening of the isthmus and $1.2 \mathrm{~mm}$ opening of the gingival wall. The cavity walls of the preparation were tapered 6 to $10^{\circ}$. The functional $(2 \mathrm{~mm})$ and non-functional $(1.5 \mathrm{~mm})$ cusps were reduced considering the specific design of each group. The non-retentive preparation following the natural tooth morphology ( $2 \mathrm{~mm}$ on functional cups, 1.5 mm on non-functional cusp), all angles and walls smooth and rounded [23-27].

After forming the surfaces, they were transformed into solids to provide delimitation of the structures that were studied. These volumes were exported in STP format (Standard for the Exchange of Product Model Data) so that the software (ANSYS 17.2, ANSYS Inc., Houston, TX, USA) for pre and post processing of finite element analysis can be used. The designed structures were: tooth with onlay preparation (functional or non-functional cusp), onlay, resin cement layer, periodontal ligament and alveolar bone composed by cortical and cancellous bone tissues.

A)

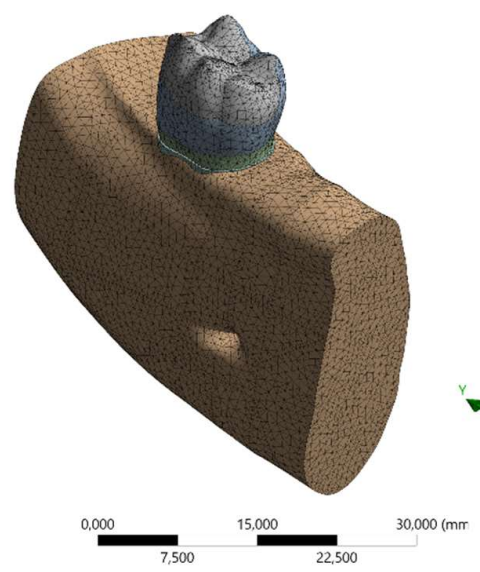

B)

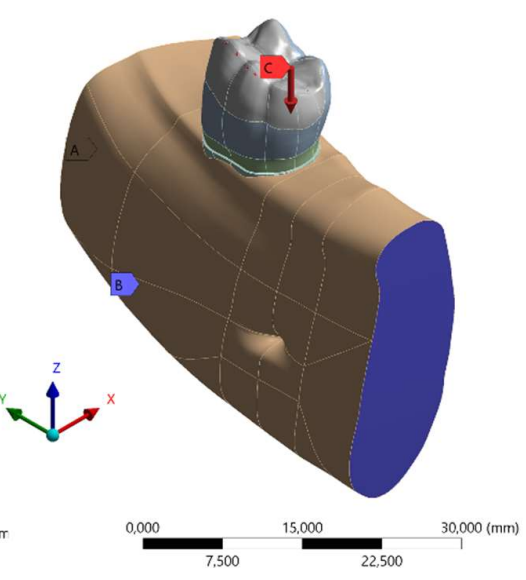

C)

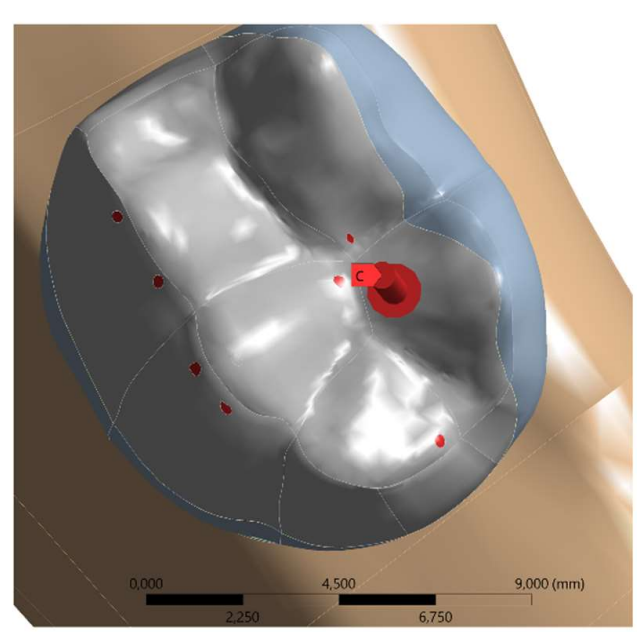

Figure 1. Numerical model processing. A) Mesh generation. B) Fixation of the system. C) Axial load application in occlusal points.

After importing the geometries, the meshes were made, the density was adjusted to obtain sufficient and accurate results. For that, the Ansys 19.2 Software (ANSYS Inc., Houston, TX, USA) was used, in which meshes of quadratic tetrahedral elements are used, 
characterized by pyramids with a triangular base, with a knot in each vertex and another in the center of each edge, totaling 10 nodes per element. This type of volume element is the most suitable for reproducing complex and curved geometries, such as dental structures, as it adapts better spatially, thus being a very powerful tool for representing volumes of anatomical geometries.

After editing the models, their specific properties were assigned. At this stage, it is important to check the consistency of the physical quantities used in the model together with the homogeneity of metric systems. In this study, the proper analysis to represent the fracture test was performed by structural static analysis, in which at least two properties, among them the elastic modulus (E) in GPa and Poisson's ratio (V), must be informed. Thus, each geometry has specific properties that characterized its behavior for an assay within the limits of linearity (Table 1) [17, 28-32].

Table 1. Materials properties considered in the present study.

\begin{tabular}{ccc}
\hline Material & Elastic Modulus (GPa) & Poisson Ratio \\
\hline Enamel & 84.1 & 0.33 \\
\hline Dentin & 18.6 & 0.32 \\
\hline Lithium Disilicate (e.max CAD & 102.7 & 0.21 \\
\hline Resin Composite (Grandio Blocs) & & 0.26 \\
\hline Resin cement (Multilink N) & 18 & 0.7 \\
\hline Periodontal Ligament & 8.2 & 0.49 \\
\hline Cortical Bone & 0.050 & 1.14 \\
\hline
\end{tabular}

The relationship between the geometries determines the transmission of the existing tensions from one element to other at the interface region, thus, it is necessary to define the contacts. In this study, they were all considered bonded.

For the simulation of the boundary conditions, in all models, the displacement in all directions was restricted and the load applied by simulating a force of $100 \mathrm{~N}$ [33]. A vertical load on the occlusal surface perpendicular to the load axis simulating the centric contact point was applied.

\section{Results}

The visualization of the results of analysis by finite element method was performed qualitatively using a color stress map, in which each fringe represents a range of stresses or deformations generated in the evaluated structures. For the analysis of the results, the Maximum Principal stress (MPa) was used to assess the stress distribution and magnitude in the restoration, cement layer and dental substrate. 
The numerical results are plotted in colorimetric stress maps in Figures 2-4, and the highest values of the Tensile Stress $(\mathrm{MPa})$ are summarized in Table 2.

A)
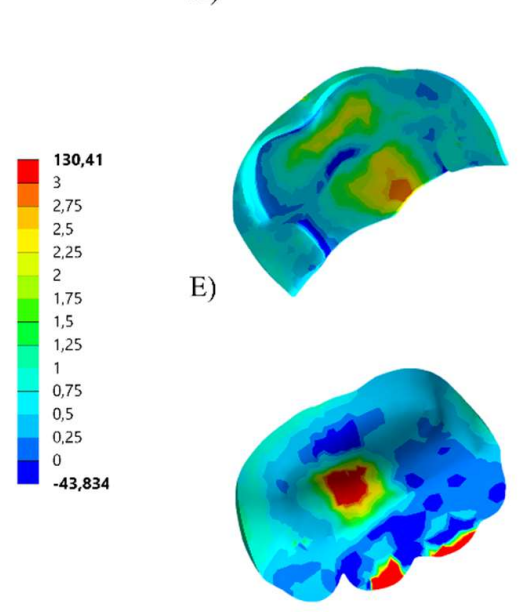

B)

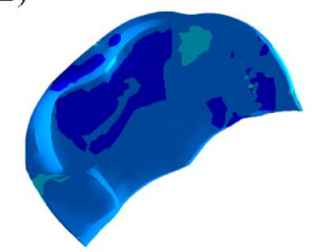

F)

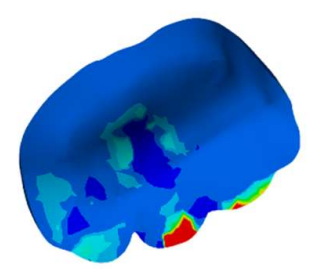

C)

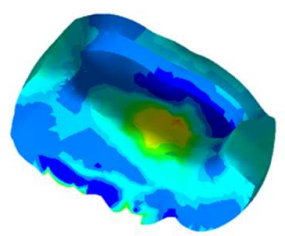

G)

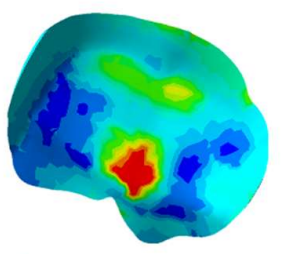

D)

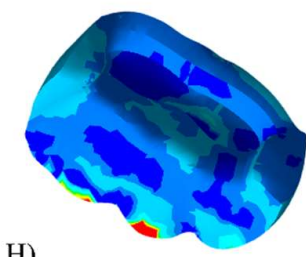

H)

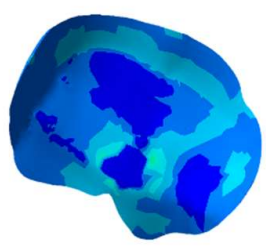

Figure 2. Maximum principal stress distribution in the restoration's intaglio surface. A) LD TFC. B) RC TFC. C) LD TNFC. D) RC TNFC. E) LD NFC. F) RC NFC. G) LD NNFC. H) RC NNFC

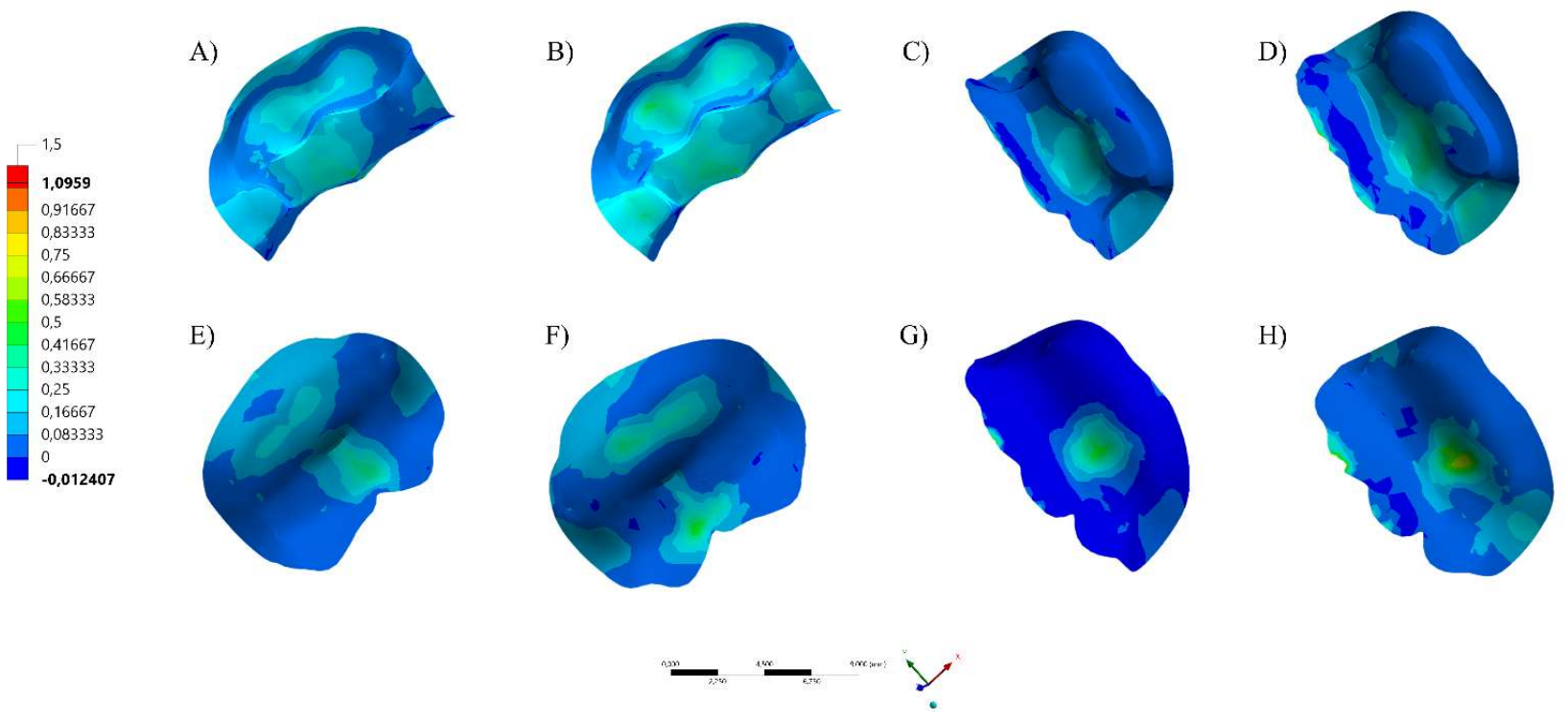

Figure 3. Maximum principal stress distribution in the cement layer. A) LD TFC. B) RC TFC. C) LD TNFC. D) RC TNFC. E) LD NFC. F) RC NFC. G) LD NNFC. H) RC NNFC.

The stress on the tooth structure (enamel and dentin) was calculated using the Maximum probe detected by the Mechanical APDL (ANSYS 19.2, ANSYS Inc., Houston, TX, USA). Observing the stress distribution on the restoration's intaglio surface (Fig. 2), LD onlays (130-95 MPa) showed higher tensile stress concentration in the center of restoration (Fig. 2A, 2C, 2E and 2G) than RC. For RC models, the stress peaks were higher (130 MPa) when TFC preparation design was considered. For LD onlays, the stress distribution on the restoration's intaglio surface showed that the preparation design influenced the stress 
distribution as well as the prepared cusp. Regardless of the restorative material, the nonretentive preparation design improved the distribution of the stress concentration to the tooth structure in comparison to the conventional retentive design. However, for conventional preparation, the stress concentration was higher than the restoration itself.

Table 2. Stress peaks measured for each geometry according to the preparation and restorative material combination.

\begin{tabular}{|c|c|c|c|c|}
\hline Material & Design & Tooth & Cement layer & Onlay \\
\hline & Traditional & 32.3 & 0.6 & 130.1 \\
\hline & & 43.1 & 0.8 & 95.9 \\
\hline \multicolumn{5}{|l|}{ Lithium Disilicate } \\
\hline & Non-retentive & 25.1 & 0.6 & 103.6 \\
\hline & & 41.1 & 0.5 & 109.1 \\
\hline & Traditional & 36.2 & 1.2 & 130.4 \\
\hline \multirow[t]{3}{*}{ Resin Composite } & & 42.1 & 1.6 & 95.5 \\
\hline & Non-retentive & 26.1 & 1.1 & 105.2 \\
\hline & & 38.3 & 0.6 & 103.4 \\
\hline
\end{tabular}

A)

E)
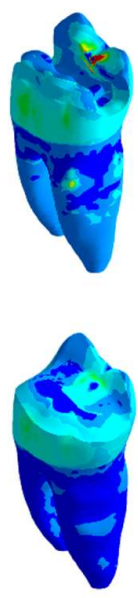

B)

F)
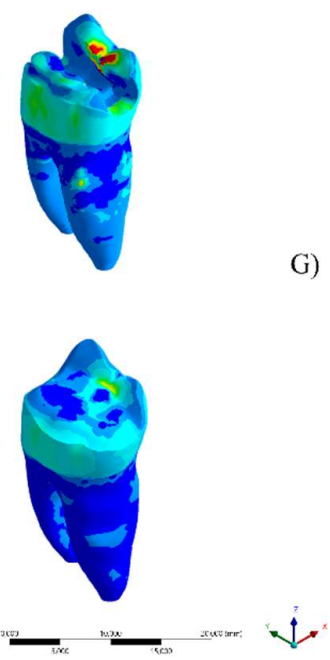

C)

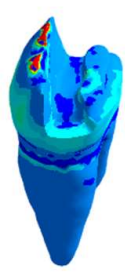

G)

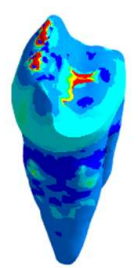

D)

H)
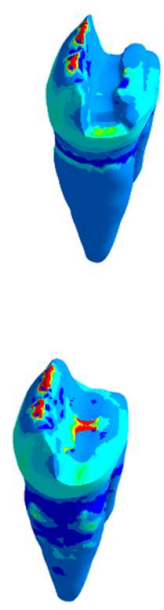

Figure 4. Maximum principal stress distribution in the tooth structure. A) LD TFC. B) RC TFC. C) LD TNFC. D) RC TNFC. E) LD NFC. F) RC NFC. G) LD NNFC. H) RC NNFC. 


\section{Discussion}

The traditional retentive onlay preparation protocols or guidelines were based on classic studies $[34,35]$ where healthy tissue was often not preserved and cusp coverage is indicated if the cavity extension was two-thirds or greater than the distance from any primary groove to the tip of the cusp. Based on the results of the finite element analysis of this study, the non-retentive preparation design showed a more favorable behavior and reduced the concentration of stresses in the tooth structure compared to the conventional retentive design.

Restorative dentistry has currently experienced a dramatic increase in minimally invasive restorations. Dentists in order to preserve as much dental structure as possible are constantly changing the traditional guidelines for the design of non-retentive preparations [23]. In addition, scientific evidence on enamel and dentin adhesion techniques are reliable, and studies have shown adequate mechanical behavior for non-retentive preparations under load [36]. These data corroborate the present study, considering that the non-retentive preparation presented the lowest stress concentration values in all analyzed structures. The less retentive preparation usually has a greater amount of enamel, which tissue has better adhesion.

Dental adhesive systems play a vital role in today's restorative dentistry [37]. These adhesive restorations substantially decrease the amount of tooth reduction required during the cavity preparation process, since adhesive restorations do not require extensions for retention [22-25]. It is important to note that most of the margin of the restoration is placed on the enamel, which serves as an excellent bonding surface for the adhesive system. Therefore, the present study's results suggest that the retention longevity and functionality of the restoration can be therefore increased.

The decision to cover the functional or non-functional cusp in partial coverage preparations may be due to the amount of remaining dental structure [24,38]. In the present study, the reduction of functional or non-functional cusps was compared, with the result that when the non-functional cusp was prepared, the stress on the functional cusp increased regardless of the type of preparation. From a clinical point of view, on teeth that already have the worn non-functional cusp, it would be indicated to perform a non-retentive preparation and restore with composite resin in order to be more conservative when not preparing the functional cusp.

The use of ceramics can be indicated in clinical settings where the traditional form of mechanical retention is limited and may allow non-retentive dental preparations, as shown in the stress distribution values on the internal surface of the restoration in this study. As the technologies and CAD/CAM materials have been improved and are being developed, the design of the preparation margin will not present a significant difference during the manufacturing process $[39,40]$.

As no consensus has been reached on how much to wear in onlay preparations today, the guidelines should be geared towards making decisions about when to prepare and what type of material is most appropriate. In line with this clinical philosophy, resin or ceramic onlays are now considered viable alternatives to full coverage crowns, with success exceeding $90 \%$ in 10 years [41]. However, manufacturers fail to provide guidance on when cusp coverage with ceramic material is indicated.

The design of this study focused on covering the functional or non-functional cusp with two types of preparation of the lower first molar tooth, the results are applicable only for this type of case. The designs of non-retentive preparations used in this study can, theoretically, minimize the concentration of stresses on the tooth structure, however this is transferred to the restoration, so it is important to follow those restorations while in service. 


\section{Conclusions}

Within the limitations of this study, considering only the stress magnitude it is possible to appreciate that:

1. Both restorative materials present a suitable applicability in onlay treatments, however preferable non-retentive preparation designs should be performed.

2. The functional-cusps preparation is preferred instead of the non-functional-cusps preparation aiming to reduce the stress in the tooth structure. However when it is not possible to preserve an already missing functional-cusps, the use of resin composite can be suggested to reduce the stress magnitude.

Author Contributions: Conceptualization, P.L.B.S.; J.P.M.T.; G.S.A.; A.L.S.B.; E.B. and P.A.; methodology, J.P.M.T.; G.S.A.; A.L.S.B.; and P.A.; software, A.L.S.B; validation, P.L.B.S.; L.M.C.; A.M.O.D.P; and P.A.; formal analysis, P.L.B.S. and A.L.S.B.; investigation, P.L.B.S.; L.M.C.; J.P.M.T.; A.M.O.D.P.; G.S.A.; A.L.S.B.; E.B. and P.A.; resources, A.L.S.B.; E.B.; and P.A.; data curation, P.L.B.S.; writing - original draft preparation, P.L.B.S.; L.M.C.; G.S.A. and E.B.; writing-review and editing, J.P.M.T.; A.M.O.D.P.; A.L.S.B. and P.A.; visualization, P.L.B.S. and L.M.C.; supervision, A.L.S.B. and E.B.; project administration, J.P.M.T. and G.S.A.; funding acquisition, A.L.S.B and P.A. All authors have read and agreed to the published version of the manuscript.

Funding: This research received no external funding.

Data Availability Statement: Data available on request.

\section{Acknowledgments: None}

Conflicts of Interest: The authors declare no conflict of interest.

\section{References}

1. Lien, W.; Roberts, H.W.; Platt, J.A.; Vandewalle, K.S.; Hill, T.J.; Chu, T.M. Microstructural evolution and physical behavior of a lithium disilicate glass-ceramic. Dent Mater 1016, 2015;31(8):928-940, 05003.

2. Saavedra, G. de S.F.A.; Tribst, J.P.M.; Ramos, N. de C.; Melo, R.M. de; Rodrigues, V.A.; Ramos, G.F.; Bottino, M.A. Feldspathic and lithium disilicate onlays with a 2-year follow-up: Split-mouth randomized clinical trial. Braz. Dent. J. 2021, 32, 53-63.

3. Rauch, A.; Reich, S.; Dalchau, L.; Schierz, O. Clinical survival of chair-side generated monolithic lithium disilicate crowns:10-year results. Clin. Oral Investig. 2018, 22, 1763-1769.

4. Seydler, B.; Schmitter, M. Clinical performance of two different CAD/CAM-fabricated ceramic crowns: 2-Year results. J Prosthet Dent 1016, 2015;114(2):212-216, 02016.

5. Pieger, S.; Salman, A.; Bidra, A.S. Clinical outcomes of lithium disilicate single crowns and partial fixed dental prostheses: a systematic review. J. Prosthet. Dent. 2014, 112, 22-30.

6. Alkadi, L.; Ruse, N.D. Fracture toughness of two lithium disilicate dental glass ceramics. J. Prosthet. Dent. 2016, 116, 591-596.

7. Imamura, Y.; Sato, Y.; Kitagawa, N.; Uchida, K.; Osawa, T.; Omori, M.; Okada, Y. Influence of occlusal loading force on occlusal contacts in natural dentition. J. Prosthodont. Res. 2015, 59, 113-120.

8. Koc, D.; Dogan, A.; Bek, B. Bite force and influential factors on bite force measurements: A literature review. Eur. J. Dent. 2010, 04, 223-232.

9. Penteado, M.M.; Tribst, J.P.M.; Dal Piva, A.M.; Ausiello, P.; Zarone, F.; Garcia-Godoy, F.; Borges, A.L. Mechanical behavior of conceptual posterior dental crowns with functional elasticity gradient. Am. J. Dent. 2019, 32, 165-168.

10. Lee, A.; Swain, M.; He, L.; Lyons, K. Wear behavior of human enamel against lithium disilicate glass ceramic and type III gold. J. Prosthet. Dent. 2014, 112, 1399-1405.

11. Kelly, J.R. Dental ceramics: current thinking and trends. Dent. Clin. North Am. 2004, 48, viii, 513-30. 
12. Archibald, J.J.; Santos, G.C., Jr; Moraes Coelho Santos, M.J. Retrospective clinical evaluation of ceramic onlays placed by dental students. J. Prosthet. Dent. 2018, 119, 743-748.e1.

13. Mounajjed, R.; M Layton, D.; Azar, B. The marginal fit of E.max Press and E.max CAD lithium disilicate restorations: A critical review. Dent. Mater. J. 2016, 35, 835-844.

14. Ahlers, M.O.; Mörig, G.; Blunck, U.; Hajtó, J.; Pröbster, L.; Frankenberger, R. Guidelines for the preparation of CAD/CAM ceramic inlays and partial crowns. Int. J. Comput. Dent. 2009, 12, 309-325.

15. De Carvalho, A.G.; Andrade, G.; Tribst, J.M.; Grassi, E.; Ausiello, P.; Saavedra, G.; Bressane, A.; Melo, R.M.; Borges, A. Mechanical Behavior of Different Restorative Materials and Onlay Preparation Designs in Endodontically Treated Molars. Materials 2021, 14.

16. Silva, L.H. da; Lima, E. de; Miranda, R.B. de P.; Favero, S.S.; Lohbauer, U.; Cesar, P.F. Dental ceramics: a review of new materials and processing methods. Braz. Oral Res. 2017, 31, e58.

17. de Andrade, G.S.; Augusto, M.G.; Simões, B.V.; Pagani, C.; Saavedra, G. de S.F.A.; Bresciani, E. Impact of simulated toothbrushing on surface properties of chairside CAD-CAM materials: An in vitro study. J. Prosthet. Dent. 2021, 125, 469.e1469.e6.

18. Grassi, E.D.A.; de Andrade, G.S.; Tribst, J.P.M.; Machry, R.V.; Valandro, L.F.; Ramos, N. de C.; Bresciani, E.; Saavedra, G. de S.F.A. Fatigue behavior and stress distribution of molars restored with MOD inlays with and without deep margin elevation. Clin. Oral Investig. 2021, doi:10.1007/s00784-021-04219-6.

19. Swain, M.V.; Coldea, A.; Bilkhair, A.; Guess, P.C. Interpenetrating network ceramic-resin composite dental restorative materials. Dent. Mater. 2016, 32, 34-42.

20. Ruse, N.D.; Sadoun, M.J. Resin-composite blocks for dental CAD/CAM applications. J. Dent. Res. 2014, 93, 1232-1234.

21. Ausiello, P.; Ciaramella, S.; Di Rienzo, A.; Lanzotti, A.; Ventre, M.; Watts, D.C. Adhesive class I restorations in sound molar teeth incorporating combined resin-composite and glass ionomer materials: CAD-FE modeling and analysis. Dent. Mater. 2019, 35, 1514-1522.

22. Pereira, J.R.; McDonald, A.; Petrie, A.; Knowles, J.C. Effect of cavity design on tooth surface strain. J. Prosthet. Dent. 2013, 110, 369-375.

23. Politano, G.; Van Meerbeek, B.; Peumans, M. Nonretentive bonded ceramic partial crowns: Concept and simplified protocol for long-lasting dental restorations. J. Adhes. Dent. 2018, 20, 495-510.

24. Andrade GS; Ab, P.; Jp, T.; Ep, C.; Al, B.; Siqueira Ferreira Anzaloni Saavedra G Does overlay preparation design affect polymerization shrinkage stress distribution? A 3D FEA study. Computer Methods in Biomechanics and Biomedical Engineering 2021, 11;24(9):1026-34.

25. Treglia, A.S.; Turco, S.; Ulianich, L.; Ausiello, P.; Lofrumento, D.D.; Nicolardi, G.; Miele, C.; Garbi, C.; Beguinot, F.; Di Jeso, B. Cell fate following ER stress: just a matter of "quo ante" recovery or death? Histol. Histopathol. 2012, 27, 1-12.

26. Picella, A.; Di Palma, L.; Aversa, R.; Ausiello, P. DSC kinetic characterization of dental composites using different light sources. J. Adv. Mater 2002, 22-25.

27. Martorelli, M.; Ausiello, P. A novel approach for a complete 3D tooth reconstruction using only 3D crown data. Int. J. Interact. Des. Manuf. (IJIDeM) 2013, 7, 125-133.

28. Sano, H.; Ciucchi, B.; Matthews, W.G.; Pashley, D.H. Tensile properties of mineralized and demineralized human and bovine dentin. J. Dent. Res. 1994, 73, 1205-1211.

29. Wendler, M.; Belli, R.; Petschelt, A.; Mevec, D.; Harrer, W.; Lube, T.; Danzer, R.; Lohbauer, U. Chairside CAD/CAM materials. Part 2: Flexural strength testing. Dent. Mater. 2017, 33, 99-109. 
30. Lopes, C. de C.A.; Rodrigues, R.B.; Silva, A.L.F.E.; Simamoto Júnior, P.C.; Soares, C.J.; Novais, V.R. Degree of conversion and mechanical properties of resin cements cured through different all-ceramic systems. Braz. Dent. J. 2015, 26, 484-489.

31. Fill, T.S.; Carey, J.P.; Toogood, R.W.; Major, P.W. Experimentally determined mechanical properties of, and models for, the periodontal ligament: critical review of current literature. J. Dent. Biomech. 2011, 2011, 312980.

32. Soares, C.J.; Raposo, L.H.A.; Soares, P.V.; Santos-Filho, P.C.F.; Menezes, M.S.; Soares, P.B.F.; Magalhães, D. Effect of different cements on the biomechanical behavior of teeth restored with cast dowel-and-cores-in vitro and FEA analysis. J. Prosthodont. 2010, 19, 130-137.

33. Vianna, A.L.S. de V.; Prado, C.J. do; Bicalho, A.A.; Pereira, R.A. da S.; Neves, F.D. das; Soares, C.J. Effect of cavity preparation design and ceramic type on the stress distribution, strain and fracture resistance of CAD/CAM onlays in molars. J. Appl. Oral Sci. 2018, 26, e20180004.

34. Dal Piva, A.M. de O.; Tribst, J.P.M.; Benalcázar Jalkh, E.B.; Anami, L.C.; Bonfante, E.A.; Bottino, M.A. Minimal tooth preparation for posterior monolithic ceramic crowns: Effect on the mechanical behavior, reliability and translucency. Dent. Mater. 2021, 37, e140-e150.

35. Lima, F.F.; Neto, C.F.; Rubo, J.H.; Santos, G.C., Jr; Moraes Coelho Santos, M.J. Marginal adaptation of CAD-CAM onlays: Influence of preparation design and impression technique. J. Prosthet. Dent. 2018, doi:10.1016/j.prosdent.2017.10.010.

36. Babaei, B.; Shouha, P.; Birman, V.; Farrar, P.; Prentice, L.; Prusty, G. The effect of dental restoration geometry and material properties on Biomechanical behaviour of a treated molar tooth: A 3D finite element analysis. J. Mech. Behav. Biomed.

Mater. 2021, 104892.

37. Van Landuyt, K.L.; Snauwaert, J.; De Munck, J.; Peumans, M.; Yoshida, Y.; Poitevin, A.; Coutinho, E.; Suzuki, K.; Lambrechts, P.; Van Meerbeek, B. Systematic review of the chemical composition of contemporary dental adhesives. Biomaterials 2007, 28, 3757-3785.

38. Skorulska, A.; Piszko, P.; Rybak, Z.; Szymonowicz, M.; Dobrzyński, M. Review on polymer, ceramic and composite materials for CAD/CAM indirect restorations in dentistry-application, mechanical characteristics and comparison. Materials (Basel) 2021, 14, 1592.

39. Griffis, E.; Abd Alraheam, I.; Boushell, L.; Donovan, T.; Fasbinder, D.; Sulaiman, T.A. Tooth-cusp preservation with lithium disilicate onlay restorations: A fatigue resistance study. J. Esthet. Restor. Dent. 2020, doi:10.1111/jerd.12666.

40. Goujat, A.; Abouelleil, H.; Colon, P.; Jeannin, C.; Pradelle, N.; Seux, D.; Grosgogeat, B. Marginal and internal fit of CADCAM inlay/onlay restorations: A systematic review of in vitro studies. J. Prosthet. Dent. 2019, 121, 590-597.e3.

41. Morimoto, S.; Rebello de Sampaio, F.B.W.; Braga, M.M.; Sesma, N.; Özcan, M. Survival rate of resin and ceramic inlays, onlays, and overlays: A systematic review and meta-analysis: A systematic review and meta-analysis. J. Dent. Res. 2016, 95, 985-994. 